\title{
Upaya Pencegahan Perbedaan Diagnosis Klinis Dan Diagnosis Asuransi Dengan Diberlakukan Program Jaminan Kesehatan Nasional (JKN) Dalam Pelayanan Bpjs Kesehatan Studi Di Rsud Kota Semarang
}

\section{Efforts to Prevent Differences between Clinical and Insurance Diagnosis after Implementing the National Health Insurance Program in Services of Healthcare and Social Security Agency (Health BPJS) Study at Semarang City Public Hospital}

\author{
Faik Agiwahyuanto $^{1}$, Sudiro $^{2}$, Inge Hartini ${ }^{3}$ \\ ${ }^{1)}$ Mahasiswa Program Pascasarjana Magister Ilmu Kesehatan Masyarakat, \\ Fakultas Kesehatan Masyarakat, Universitas Diponegoro, Semarang \\ Email: fagiwahyuanto@gmail.com (+628112700925) \\ ${ }^{2)}$ Fakultas Kesehatan Masyarakat, Universitas Diponegoro, Semarang \\ ${ }^{3)}$ Bidang Pendidikan dan Pelatihan, Rumah Sakit St. Elisabeth, Semarang
}

\begin{abstract}
Abstrak
RSUD Kota Semarang mengalami tren kenaikan persentase perbedaan diagnosis klinis dan asuransi. Apabila hal ini terus berlanjut dapat mengarah pada upcoding (fraud). Tujuan penelitian ini adalah untuk menjelaskan proses terjadinya perbedaan diagnosis klinis dan diagnosis asuransi di rumah sakit dalam pelaksanaan Badan Penyelenggara Jaminan Sosial (BPJS) Kesehatan.

Penelitian menggunakan metode kualitatif. Informan utama yaitu dokter jaga Instalasi Gawat Darurat (IGD), dokter spesialis bedah, dan dokter spesialis penyakit dalam, sedangkan informan triangulasi yaitu Direktur rumah sakit, verifikator rumah sakit, dan Kepala Unit Rekam Medis. Hasil wawancara mendalam dengan para informan dilakukan analisis isi untuk mendapatkan proses perbedaan diagnosis klinis dan diagnosis asuransi yang mengarah pada upcoding.

Berdasarkan jawaban dari indepth interview telah terjadi perbedaan diagnosis klinis dan diagnosis asuransi di RSUD Kota Semarang. Penyebab perbedaan karena perbedaan diagnosis dan tindakan medis standar pelayanan medis dokter di RS dengan standar INA-CBGs. Untuk mencegah perbedaan diagnosis klinis dan asuransi, maka RSUD Kota Semarang sudah membentuk tim verifikator internal rumah sakit dan Clinical Micro System Team. Komite medik juga berperan membantu untuk membantu meminimalisir kejadian upcoding yaitu dengan memperbanyak jenis Clinical Pathway sebagai acuan bagi dokter untuk mendiagnosa dan menentukan jenis tindakan pada pasien.

Perbedaan diagnosis klinis dan diagnosis asuransi harus segera diselesaikan untuk mencegah terjadinya upcoding dan kerugian RS. Upaya pencegahan perbedaan tersebut dengan menambah petugas dan pelatihan koding, membuat dan memperbanyak algoritma clinical pathway, pembentukan tim Clinical Micro System, dan monitoring dan evaluasi pelayanan medis

Kata Kunci : Diagnosis Klinis, Diagnosis Asuransi, Koding, INA-CBGs, BPJS Kesehatan, JKN

Referensi : : $40(1998-2016)$

\footnotetext{
Abstract

Percentage of clinical and insurance diagnosis differences at Semarang City Public Hospital tended to increase. If this condition remained, it would lead to upcoding (fraud). The aim of this
} 
study was to explain a process of clinical and insurance diagnosis at a hospital in the implementation of Healthcare and Social Security Agency (Health BPJS).

This was a qualitative study. Main informants consisted of doctors at an emergency room, surgeons, and internists. Informants for triangulation purpose consisted of a Hospital Director, a hospital verifier, and a head of Medical Record Unit. Data were analysed using content analysis.

The results of this research showed that there were any differences in clinical and insurance diagnosis at Semarang City Public Hospital. The cause of these differences was due to differences in diagnosis and medical treatment between medical service standard of doctors at the hospital and a standard of INA-CBGs. To prevent the differences of clinical and insurance diagnosis, the Semarang City Public Hospital had formed an internal verifier team of the hospital and a Clinical Micro System team. A medical committee had a role to minimise the occurrence of upcoding by multiplying kinds of Clinical Pathway as a reference for doctors in diagnosing and determining kinds of treatments for patients.

The differences of clinical and insurance diagnosis must be equated to prevent the occurrence of upcoding and disadvantage of the hospital. Efforts to prevent these differences are by adding officers, training coding, making and multiplying algorithm of clinical pathway, forming a team of Clinical Micro System, and monitoring and evaluating medical services.

Keywords : Clinical Diagnosis, Insurance Diagnosis, Coding, INA-CBGs, Health BPJS,NHI Bibliography : 40 (1998-2016)

\section{Pendahuluan}

Rumah sakit di Negara Indonesia untuk menentukan tarif ketika diberlakukan sistem JKN adalah berdasarkan INA-CBGs. Case Base Group adalah pengelompokan diagnosa penyakit yang berdasarkan grouping dari tarif itu sendiri, dengan demikian pemberian dan pemberlakuan tarif di rumah sakit pada pengelompokan tersebut dinamakan diagnosa asuransi. Sedangkan dokter-dokter di rumah sakit masih menggunakan diagosa klinis per tindakan dan sesuai dengan prosedur pemeriksaan dan hasil diagnosis medis. Hal tersebut memunculkan perbedaan ketentuan diagnosis dokter sebagai diagnosis klinis dan ketentuan diagnosis BPJS Kesehatan dalam grouping sebagai diagnosis asuransi. Rumah sakit sudah melakukan upaya untuk mempersempit tindakan tersebut dengan membuat Clinical Micro System, namun upaya ini tidak mudah dalam pelaksanaannya. Bagi dokter-dokter yang praktek upaya ini tidak masuk akal, karena perbedaan antara diagnosis yang ditegakkan dokter dan diagnosis grouping dari Software INA-CBGs cenderung diatasi dengan tindakan upcoding oleh verifikator. ${ }^{1-18}$

Studi pendahuluan di RSUD berdasarkan data rekam medis tahun 2012 hingga pertengahan tahun 2015 pada pasien yang menggunakan ASKES, JAMKESMAS, JAMKESKOT, JAMSOSTEK, dan BPJS Kesehatan bahwa rumah sakit tersebut mengalami kenaikan kasus perbedaan diagnosis klinis dan diagnosis asuransi yang dapat mengarah kepada upcoding.

INA-CBGs proses penentuannya menggunakan acuan dari Prof. Bob Fetter dan John Thompson dari DRG-Malaysia. Indonesia menerapkan sistem tersebut menggunakan acuan tarif rumah sakit negeri dari seluruh kota/kabupaten dan propinsi di Indonesia. Tarif RS tersebut rata-rata tidaklah sama, selain itu tarif dari RS Negeri untuk pengelompokkan diagnosis pasti lebih murah dari RS Swasta di Indonesia. ${ }^{9,16}$

Disamping itu penghitunganpenghitungan tarif sesuai program INA-CBGs cenderung memakai diagnosis primer dan diagnosis sekunder untuk menentukan tingkat keparahan pasien, tetapi software INA-CBGs masih banyak kelemahannya. Contohnya pada diagnosis KPD (Ketuban Pecah Dini) dan SC (Sectio Caesarea), verifikator memasukkanSC yang menjadi primary diagnosis dan sekundernya KPD dan Single Life birth; akan berbeda tarif yang muncul dengan KPD menjadi primary diagnostic dan SC menjadi secondary diagnostic. ${ }^{9,16}$ Kelemahan software ini apabila dimasukkan diagnosis primer 
terlebih dahulu akan berbeda tarif yang muncul dengan verifikator memasukkan diagnosis sekunder terlebih dahulu, sehingga RS cenderung untuk menyikapi input data pada diagnosis sekunder untuk mendapatkan tarif klaim yang lebih tinggi.

Oleh karena itu peneliti tertarik untuk mengetahui, menjelaskan, dan menganalisis penyebab perbedaan diagnosis klinis dan diagnosis asuransi, antara lain persepsi verifikator dan dokter dalam memahami rukam medis, klaim yang lama untuk dicairkan, dan software INA-CBGs bermasalah, serta upaya yang telah dilakukan RSUD Kota Semarang untuk mengantisipasi hal tersebut.

\section{Metode Penelitian}

Penelitian ini menggunakan desain deskriptif kualitatif pendekatan fenomenologi dan dilakukan di Rumah Sakit Umum Daerah Kota Semarang. Informan penelitian terbagi menjadi 2 bagian, yaitu informan utama antara lain 1 orang dokter jaga IGD, 1 orang dokter spesialis bedah, dan 1 orang dokter spesialis penyakit dalam; dan informan triangulasi adalah 1 orang Direktur RSUD, 1 orang verifikator rumah sakit, dan 1 orang Ketua Bidang Rekam Medis dan Koding melalui in depth interview. Hasil wawancara dianalisis dengan content analysis yaitu membandingkan informasi yang diperoleh dari informan dengan teori yang sudah ada, serta mengelompokkan data untuk ditarik kesimpulan. Keterangan Kelaikan Etik (Ethical Clearence) diperoleh dari Komisi Etik Penelitian Kesehatan Fakultas Kesehatan Masyarakat Universitas Diponegoro dengan Surat Keterangan No. 28/EC/FKM/2016.

\section{Hasil}

Penelitian ini dilakukan pada bulan MaretApril 2016. Hasil analisis wawancara mendalam terangkum dalam hasil penelitian sebagai berikut:

1. Perbedaan tarif klaim rumah sakit dan tarif klaim BPJS Kesehatan

Perbedaan diagnosis klinis dan diagnosis asuransi terjadi pada penulisan rekam medis oleh dokter, karena terjadi perbedaan persepsi dalam pembacaan rekam medis pasien antara pihak verifikator dengan dokter yang bertugas memeriksa pasien. Pihak verifikator internal rumah sakit dan verifikator BPJS Kesehatan untuk menentukan tarif memakai pedoman software INA-CBGs, sedangkan penentuan diagnosisnya baik dari verifikator internal rumah sakit, verifikator BPJS Kesehatan, dan dokter memakai pedoman ICD-IX dan ICD-X.

Verifikator internal rumah sakit dalam bekerjanya memakai software rumah sakit dalam menentukan tarif dan untuk menentukan diagnosis berdasarkan $I C D-I X$ dan $I C D-X$, sedangkan verifikator BPJS Kesehatan untuk menentukan tarif memakai software INA-CBGs dan untuk memnentukan diagnosis juga berdasarkan $I C D-I X$ dan $I C D-X$. Perbedaan dalam menentukan tarif oleh RS dan BPJS Kesehatan menimbulkan perbedaan pada output tarifnya (tarif rumah sakit dan tarif BPJS Kesehatan). Bahkan di pelayananpelayanan tertentu seperti bedah, obsgin hasil dari pemberlakuan tarif adalah merugikan RS, sedangkan untuk pelayanan-pelayanan non-bedah dan nonobsgin umumnya menguntungkan RS.

Kesimpulannya adalah perbedaan diagnosis klinis dan diagnsis asuransi adalah pemakaian software RS dan software INA-CBGs untuk menentukan tarif.

2. Penyebab perbedaan diagnosis klinis dan diagnosis asuransi

Penyebab perbedaan diagnosis klinis dan diagnosis asuransi sangatlah beragam, antara lain latar belakang pendidikan verifikator internal RS dan verifikator BPJS Kesehatan. Rata-rata verifikator BPJS Kesehatan berlatar belakang pendidikan non-kesehatan, sedangkan verifikator internal RS berlatar belakang pendidikan dari ilmu kesehatan. Perbedaan tersebut menyebabkan permasalahan dalam menganalisis dan membaca serta menginterprestasikan rekam medis yang ditulis dokter.

Penyebab selanjutnya adalah perbedaan besar tarif klaim yang keluar, hal ini didasarkan dari diagnosis yang diinputkan ke software yang berbeda, meskipun sama-sama keduanya mengacu 
pada $I C D-I X$ dan $I C D-X$ untuk penegakan diagnosis yang telah ditulis oleh dokter.

Seringnya pihak verifikator internal RS untuk merefisi data rekam medis pasien yang telah ditulis oleh dokter. Data rekam medis tersebut terdapat penyesusaian dari diagnosis dokter yang asli ke diagnosis yang telah dimodifikasi untuk menyesuaikan hal tersebut pada software rumah sakit dan INA-CBGs.

3. Upaya pencegahan perbedaan diagnosis klinis dan asuransi

Upaya yang dilakukan pihak rumah sakit untuk menangani permasalah tersebut antara lain membuat pengaturan kepegawaian bagi petugas koding ditempatkan pada divisi atau bagian yang disendirikan antara koding internal rumah sakit dan koding INA-CBGs dari BPJS Kesehatan, selain itu pihak manajerial juga membuat badan independen bernama Clinical Micro System yang bertanggungjawab langsung kepada Direktur RSUD Kota Semarang.

Pembenahan yang dilakukan selain dari internal rumah sakit, pihak BPJS Kesehatan juga harus melakukan pembenahan sistem yang tengah dijalankan ini, seperti perbaikan software INA-CBGs, pembatasan wewenang dari petugas BPJS Kesehatan dalam pengambilan keputusan internal rumah sakit, regulasi yang dikeluarkan pihak BPJS Kesehatan kepada rumah sakit sebelumnya harus disosialisasikan terlebih dahulu kepada seluruh rumah sakit dan provider pelayanan kesehatan selain rumah sakit yang berhubungan dengan BPJS Kesehatan.

\section{Pembahasan}

1. Perbedaan tarif klaim rumah sakit dan tarif klaim BPJS Kesehatan

Pada penelitian terjadi perbedaan tarif klaim rumah sakit dan tarif klaim BPJS Kesehatan. Hal tersebut terjadi karena perbedaan penafsiran dan persepsi dalam membaca rekam medis yang ditulis oleh dokter berdasar tanda dan gejala pasien yang diperiksa. Pihak verifikator internal rumah sakit khususnya menghadap 2 buah program yang mengeluarkan tarif pelayanan di RS tersebut, yaitu program atau software rumah sakit dan software INA-CBGs. Kedua program tersebut harus bisa sesuai atau kalau bisa pihak rumah sakit mendapatkan keuntungan dari perbedaan tarif klaim tersebut.

Kasus yang terjadi pada pasien yang dirawat kemudian dicatat di rekam medis oleh dokter, dan rekam medis tersebut dimasukkan ke dalam program rumah sakit dan INA-CBGS untuk diketahui tarifnya, maka akan berbeda jumlah tarifnya. Perbedaan antara tarif rumah sakit dan tarif BPJS Kesehatan, karena pemakaian software yang berbeda, walaupun dalam menegakkan diagnosis tetap mengacu pada 1 hal yaitu koding dari $I C D-I X$ dan $I C D-X$. Perbedaan tersebut membuat permasalahan yang banyak sekali, dan menimbulkan celah untuk melakukan tindakan fraud upcoding dengan berbagai alasan.

Fraud pelayanan kesehatan merupakan salah satu faktor dominan yang menyebabkan meningkatnya biaya pelayanan kesehatan di Amerika Serikat. ${ }^{19-25}$ Upcoding adalah istilah yang tidak didefinisikan dalam peraturan namun secara umum dipahami sebagai penagihan untuk layanan pada tingkat kompleksitas yang lebih tinggi dari layanan yang sebenarnya disediakan atau didokumentasikan dalam file. ${ }^{26-27}$

2. Penyebab perbedaan diagnosis klinis dan diagnosis asuransi

Latar belakang pendidikan pada pegawai yang menangani secara langsung tentang tarif pada rumah sakit tersebut, baik tarif yang dikeluarkan berasal dari software rumah sakit dan software INA$C B G s$ sangat berpengaruh, karena hal yang dihadapi adalah masalah kesehatan. Kecenderungan yang terjadi di rumah sakit adalah verifikator BPJS Kesehatan bukan berasal dari latar belakang pendidikan non-kesehatan, tetapi untuk verifikator internal rumah sakit sudah berlatar belakang pendidikan rekam medis.

Penyebab lainnya adalah perbedaan besar tarif klaim yang keluar, karena perbedaan software saja, contohnya 
adalah persalinan pada pasien dengan indikasi sungsang atau presentasi bokong (presbo), seharusnya secara medis adalah masuk pada tindakan SC, namun apabila dimasukkan ke dalam program INA-CBGs justru dimasukkan ke persalinan pervaginam. Kalau dimasukkan ke dalam $S C$ harus ada komplikasi tambahan yaitu KPD >48 jam. Berdasarkan masalah tersebut, tarif yang keluar di software INA-CBGs berbeda, karena tarif persalinan pervaginam lebih murah daripada tindakan sectio caesarean, padahal verifikator dan dokter mengacu pada ICD-IX dan ICD-X untuk menegakkan diagnosis medis.

Kesimpulannya adalah penyebab perbedaan diagnosis klinis dan diagnosis asuransi adalah masalah pencairan klaim dan klaim ketika bisa keluar agar nominalnya besar, walaupun pemakaian software rumah sakit dan software INA$C B G s$ harus dilakukan revisi oleh pihak verifikator internal rumah sakit dan BPJS Kesehatan.

3. Upaya pencegahan perbedaan diagnosis klinis dan asuransi

Untuk mengindari perbedaan diagnosis klinis dan asuransi, RS menempatkan petugas koding. Pada koding internal rumah sakit dan koding INA-CBGs dari BPJS Kesehatan.

RS membentuk badan independen yang disebut Clinical Micro System Team. Tim tersebut bertanggung jawab langsung kepada Direktur RSUD Kota Semarang, yang terdiri dari jajaran manajerial rumah sakit, pimpinan verifikator internal rumah sakit, pimpinan rekam medis, pimpinan SIM rumah sakit, dan komite medik. Tugas dari tim tersebut adalah menengahi permasalahan dari dokter dengan BPJS Kesehatan, menjaga citra pelayanan kesehatan dokter dan tim medis kepada pasien, dan untuk mengatasi masalah sistem JKN. ${ }^{28-40}$

\section{Kesimpulan}

Permasalahan perbedaan diagnosis klinis dan diagnosis asuransi di RSUD Kota Semarang mulai terjadi ketika penerapan BPJS
Kesehatan. Hal ini disebabkan pada pencairan klaim pasien BPJS Kesehatan.

Perbedaan terjadi pada penentuan dan penulisan diagnosis klinis dan diagnosis asuransi yang berbeda nilainya dengan klaim rumah sakit yang ditulis di rekam medis.

Upaya pencegahan yang dilakukan pihak rumah sakit untuk menangani permasalah tersebut antara lain dengan membuat pengaturan kepegawaian bagi petugas koding internal rumah sakit dan koding INA-CBGs dari BPJS Kesehatan secara terpisah. Selain itu pihak manajerial juga membuat badan independen bernama Clinical Micro System yang bertanggungjawab langsung kepada Direktur RSUD Kota Semarang.

Selain dari internal rumah sakit, pihak BPJS Kesehatan juga harus melakukan pembenahan sistem yang tengah dijalankan ini, seperti perbaikan software INA-CBGs, pembatasan wewenang dari petugas BPJS Kesehatan dalam pengambilan keputusan internal rumah sakit, regulasi yang dikeluarkan pihak BPJS Kesehatan kepada rumah sakit sebelumnya harus disosialisasikan terlebih dahulu kepada seluruh rumah sakit dan provider pelayanan kesehatan selain rumah sakit yang berhubungan dengan BPJS Kesehatan.

\section{DAFTAR PUSTAKA}

1. Anonim. Monitoring Kebijakan Penyelenggaraan Program Jaminan Kesehatan Nasional di 34 Provinsi di Indonesia : 2014 - mid 2015 Jakarta Kementerian Kesehatan Republik Indonesia; 2015 [cited 2015]. 1: [Available from: http://manajemenpembiayaankesehatan.net/.

2. Peraturan Menteri Kesehatan Nomor 28 Tahun 2014 tentang Pedoman Pelaksanaan Program Jaminan Kesehatan Nasiona.

3. Peraturan Menteri Kesehatan Republik Indonesia Nomor 71 Tahun 2013 tentang Pelayanan Kesehatan pada Jaminan Kesehatan Nasional.

4. Peraturan Pemerintah RI Nomor 85 Tahun 2013 tentang Tata Cara Hubungan antar Lembaga Badan Penyelenggara Jaminan Kesehatan Nasional. 
5. Anonim. Materi Fraud dalam Pelayanan Kesehatan Jakarta: Fakultas Kedokteran Universitas Gajah Mada; 2014 [cited 2015 4 Juli]. 1: [Available from: http://course.fk.ugm.ac.id/.

6. Krisna, A. Potensi Fraud pada Ina $C B G$ Jakarta: BPJS; 2014 [cited 20154 Juli]. Available from: www.incbg.blogspot.com.

7. Abdullah, AA. Potensi Fraud pada Pelayanan Kesehatan Era JKN dan Upaya Pencegahannya. Fraud pada BPJS. Jakarta: BPJS Kesehatan; 2015.

8. Ichsan, R. Health Insurance. Jakarta: BPJS Kesehatan Negara Indonesia; 2014.

9. Thabrany, H. Jaminan Kesehatan Nasional. 1st ed. Jakarta: PT. Rajagrafindo Persada; 2014.

10. Peraturan Presiden Nomor 111 Tahun 2013 tentang Perubahan atas Peraturan Presiden Nomor 12 Tahun 2013 tentang Jaminan Kesehatan.

11. Peraturan Menteri Kesehatan Nomor 27 Tahun 2014 tentang Petunjuk Teknis Sistem Indonesian Case Base Groups (INA-CBG's).

12. Firmanda, D. Penyusunan Clinical Pathway Rumah Sakit Bethesda Yogyakarta: Rumah Sakit Bethesda Yogyakarta; 2010 [cited 20157 Desember]. Available from: http://www.scribd.com/doc/31425811/Do dy-Firmanda-2010-Clinical-Pathway-RSBethesda.

13. Firmanda, D. Kunci Sukses dan Kendala Pengembangan Penerapan Clinical Pathways di Rumah Sakit. Jakarta: RSUP Fatmawati Jakarta; 2009.

14. Basirun. Sistem Pembiayaan dan Pembayaran Pelayanan Kesehatan Malang: RSJ Dr. Radjiman Wediodiningrat; 2011 [cited 20157 Desember]. Available from: http://www.basirun.hostzi.com/ina_cbgs.h $\underline{\text { tml. }}$.

15. Anonim. Sistem INA-CBG's 2012 [cited 20157 Desember]. Available from: http://www.klikharry.com/2012/11/21/sist em-ina-cbgs/.

16. Rahma, PA. Implementasi Clinical Pathway untuk Kendali Mutu dan Kendali
Biaya Pelayanan Kesehatan. Majalah Dental and Dental. 2013.

17. Firmanda, D. Clinical Pathways Kesehatan Anak. Jurnal Sari Pediatri. 2006; 8(3):195-208.

18. Overill, S. A Practical Guide to Care Pathways. Journal of Integrated Care. 1998; 2(3):93-8.

19. Nopiyani, Ni Made Sri, Indrayathi, dan Putu, Ayu; Listyowati, Rina; Suarjana, I Ketut; dan Januraga, Pande Putu. 2015. "Akses Jaminan Kesehatan Nasional pada Pekerja Seks Perempuan”. Kesmas. Jurnal Kesehatan Masyarakat Nasional Vol. 9, No. 4, Mei 2015, hlm. 308-3014.

20. Minister-Health-US. A Roadmap for New Physicians: Avoiding Medicare and Medicaid Fraud and Abuse. Report Fraud. United State: U.S. Department of Health \& Human Services; 2011.

21. Sulaeman, Endang, dkk. 2015. Peran Kepemimpinan, Modal Sosial, Akses Informasi serta Petugas dan Fasilitator Kesehatan dalam Pemberdayaan Masyarakat Bidang Kesehatan. Kesmas: Jurnal Kesehatan Masyarakat Nasional Vol. 9, No. 4, Mei 2015, hlm. 353-361.

22. Minister-Health-US. Medicare Fraud and Abuse : A Serious Problem that Requires Your Attention. Protecting Yourself \& Medicare from Fraud. United State: Medical Learning Network; 2014.

23. Lutfiah, Umi, dkk. 2015. Ketidaktepatan Sasaran Jaminan Kesehatan Masyarakat Berdasarkan Kriteria Miskin Pendataan Program Perlindungan Sosial”. Kesmas. Jurnal Kesehatan Masyarakat Nasional Vol. 9, No. 4, Mei 2015, hlm. 362-368.

24. Minister-Health-US. Medicare Fraud and Abuse: Prevention, Detection, and Reporting. Medicare Learning Network. United State: Department of Health and Human Services; 2014.

25. Sutisna, Tri Wisesa, dkk. Penerapan Sistem Remunerasi dan Kinerja Pelayanan”. Kesmas. Jurnal Kesehatan Masyarakat Nasional Vol. 10, No. 1, Agustus 2015, hlm. 14-23.

26. Department of Health \& Human ServicesUSA. Common Types of Health Care Fraud. United State of America: 
Department of Health \& Human ServicesUSA; 2012.

27. Sparrow, MK. Fraud Control in the Health Care Industry: Assessing the State of the Art. Journal of Art. 1998; 1(1):1-7.

28. Eijkenaar, Frank. 2013. Key issues in the design of pay for performance programs. Eur J Health Econ (2013) 14:117-131. DOI 10.1007/s10198-011-0347-6.

29. Liu, Liping dan Zhu, Dan. 2012. An integrated e-service model for electronic medical records. Original Article. Inf Syst E-Bus Manage (2013) 11:161-183. DOI 10.1007/s10257-012-0188-6. SpringerVerlag 2012.

30. Somogyva'ri, Ma'rta. 2012. The Costs of Organisational Injustice in the Hungarian Health Care System.Original Article. J Bus Ethics (2013) 118:543-560. DOI 10.1007/s10551-012-1600-3. Springer Science+Business Media Dordrecht 2012.

31. Borghi, Josephine, et.al. 2013. Promoting universal financial protection: a case study of new management of community health insurance in Tanzania.Research. Health Research Policy and Systems 2013, 11:21. http://www.health-policysystems.com/content/11/1/21. Biomed Central.

32. Liou, Fen-May, et.al. 2008. Detecting hospital fraud and claim abuse through diabetic outpatient services.Original Article. Health Care Manage Sci (2008) 11:353-358. DOI 10.1007/s10729-0089054-y. Springer Science + Business Media, LLC 2008.

33. Johnson, Marina Evrim dan Nagarur, Nagen. 2015. Multi-stage methodology to detect health insurance claim fraud. Original Article. Health Care Manag Sci. DOI 10.1007/s10729-015-9317-3. Springer Science+Business Media New York 2015.

34. Liu, JunQiang dan Chen, Tao. 2013. Sleeping money: investigating the huge surpluses of social health insurance in China.Original Article. Int J Health Care Finance Econ (2013) 13:319-331. DOI 10.1007/s10754-013-9134-5. Springer Science+Business Media New York 2013.
35. Hsu, Jen-Ming, et.all. 2016. A MultiConstraint Scheme with Authorized Mechanism for the Patient Safety. Systems-Level Quality Improvement. J Med Syst (2016) 40: 123. DOI 10.1007/s10916-016-0479-4. Springer Science+Business Media New York 2016.

36. Battistella, Roger. 2013. U.S. Universal Health Coverage at a Crossroad. Int Adv Econ Res (2013) 19:409-423. DOI 10.1007/s11294-013-9428-x. International Atlantic Economic Society 2013.

37. Schatman, Michael E. dan Thoman, Janet L. 2015. Valid Psychological Injury Claims: Respecting the Needs of Survivors. Psychol. Inj. and Law (2015) 8:311-322. DOI $10.1007 / \mathrm{s} 12207-015-$ 9234-2. Springer Science+Business Media New York 2015.

38. Wagner, Anita K, et.al. 2014. Quality use of medicines within universal health coverage: hallenges and opportunities.Debate. BMC Health Services Research 2014, 14:357. http://www.biomedcentral.com/14726963/14/357. Biomed Central.

39. Goldner, Finn, et.al. 2015. Pricing the national health insurance scheme in Qatar-opportunities and challenges. Meeting Abstract. BMC Health Services Research 2015, 15 (Suppl 2): A6. http://www.biomedcentral.com/14726963/15/S2/A6. Biomed Central.

40. Department of Health \& Human ServicesUSA. Centers for Medicare \& Medicaid. In: Department of Health \& Human Services-USA. United State of America: Department of Health \& Human ServicesUSA; 2012. 